\title{
Alterações Eletrocardiográficas, Precedendo Extra-Sístoles Ventriculares
}

\author{
Electrocardiographic Abnormalities Preceding Ventricular Premature Beats
}

Eder Trezza

Faculdade de Medicina de Botucatu - UNESP - Botucatu, SP

São apresentados padrões de alterações eletrocardiográficas observadas, precedendo extra-sístoles ventriculares, em traçados obtidos durante a monitorização de pacientes submetidos a teste ergométrico. Foram analisados retrospectivamente os traçados de 1.800 testes realizados na Unidade de Registros Gráficos do Hospital das Clínicas, da Faculdade de Medicina da Unesp, campus de Botucatu, nos anos de 2001 a 2003. Os registros foram realizados em três canais (CM5, aVF e V2M), segundo a seqüência do protocolo de Bruce, para teste em esteira. Traçados-controle, pré-esforço, foram obtidos nas posições supina e ortostática, e depois a cada três minutos durante o esforço, e a cada dois minutos na fase de recuperação, em posição supina. Registros adicionais foram efetuados quando ocorreram extra-sístoles ventriculares. Foram considerados apenas os traçados com boa qualidade técnica, sem interferência, e nos quais fosse possível a comparação inequívoca do padrão dos segmentos de traçado que precediam extra-sístoles ventriculares em relação aos segmentos não sucedidos de extra-sístoles. Foram desprezados os traçados com interferência evidente ou com linha de base instável. Não foi levada em consideração a freqüência das extra-sístoles, mas apenas sua presença, mesmo quando esporádicas.

Extra-sístoles ventriculares ocorreram em 426 dos 1.800 exames (23,6\%). Alterações do segmento ST, das ondas T ou $\cup$ ou da linha de base diastólica, que constituíam modificação do padrão observado nos complexos não sucedidos de extra-sístoles, foram identificadas em 103 destes 426 exames $(24,1 \%)$.

As alterações "anunciadoras" de extra-sístoles foram as seguintes:

1 - Variação para mais ou para menos de desnivelamentos do segmento ST presentes nos complexos-controle, ou aparecimento de infra ou supradesnivelamentos previamente inexistentes (fig. 1-III, 1-IV, 2-II, 3-I, 3-II, 3-III e 3-IV).

2 - Variação para mais ou para menos da amplitude da onda $\mathrm{T}$, fosse ela previamente positiva, negativa ou com padrão minus-plus ou plus-minus (fig. 1-II, 1-III, 1-IV, 2-I, 2-III, 2-IV, 3-I e 3-III).

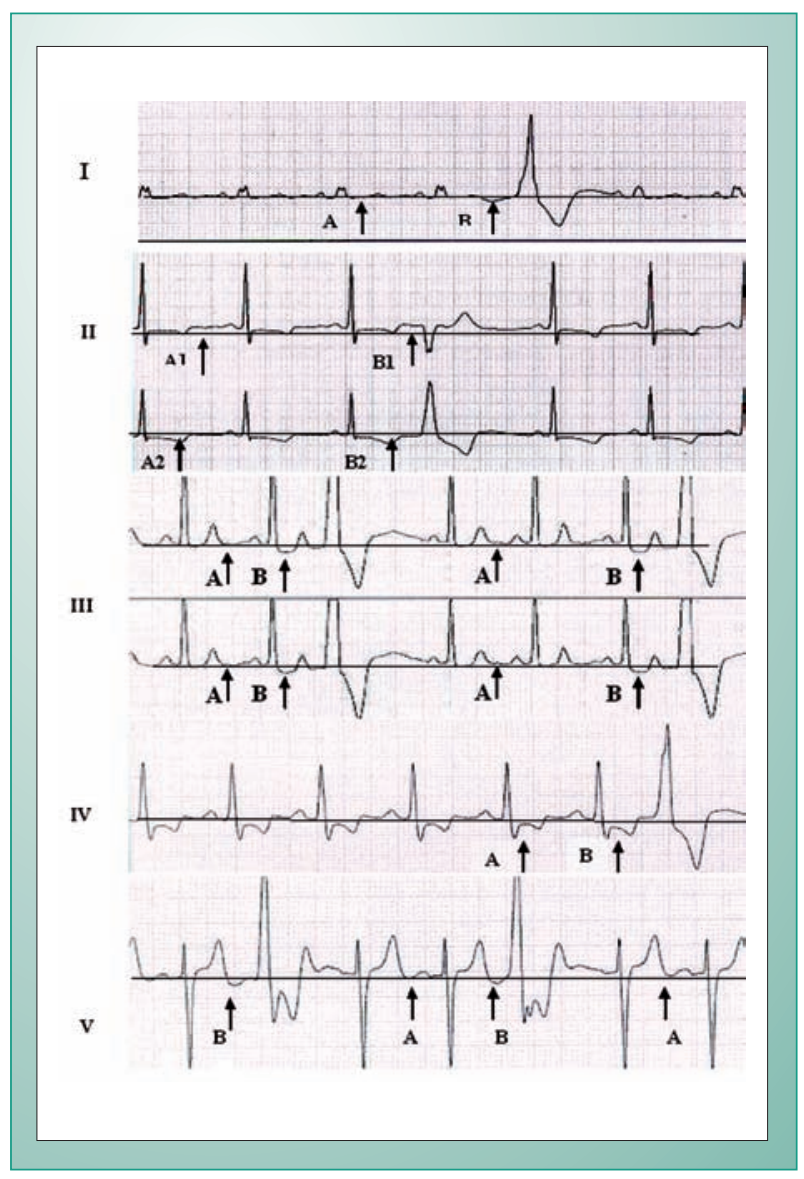

Fig. 1 - Alterações eletrocardiográficas, precedendo extra-sístoles ventriculares.

I - Infradesnivelamento da linha de base durante a diástole, iniciado como uma onda $U$ negativa.

II - Supradesnivelamento da linha de base diastólica, entre A1 e B1e discreto aumento da negatividade da onda T, entre A2 e B2.

III - Infradesnivelamento do segmento ST e da linha de base diastólica, entre os momentos $A$ e $B$.

$I V$ - Acentuação do infradesnivelamento do segmento ST de A para B. $\boldsymbol{V}$ - Aparecimento de onda $U$ negativa (ou infradesnivelamento da linha de base diastólica), quando se comparam os momentos $A$ e $B$.

\section{Palavras-chave}

Eletrocardiografia, arritmia, eletrofisiologia. 


\section{Imagem}

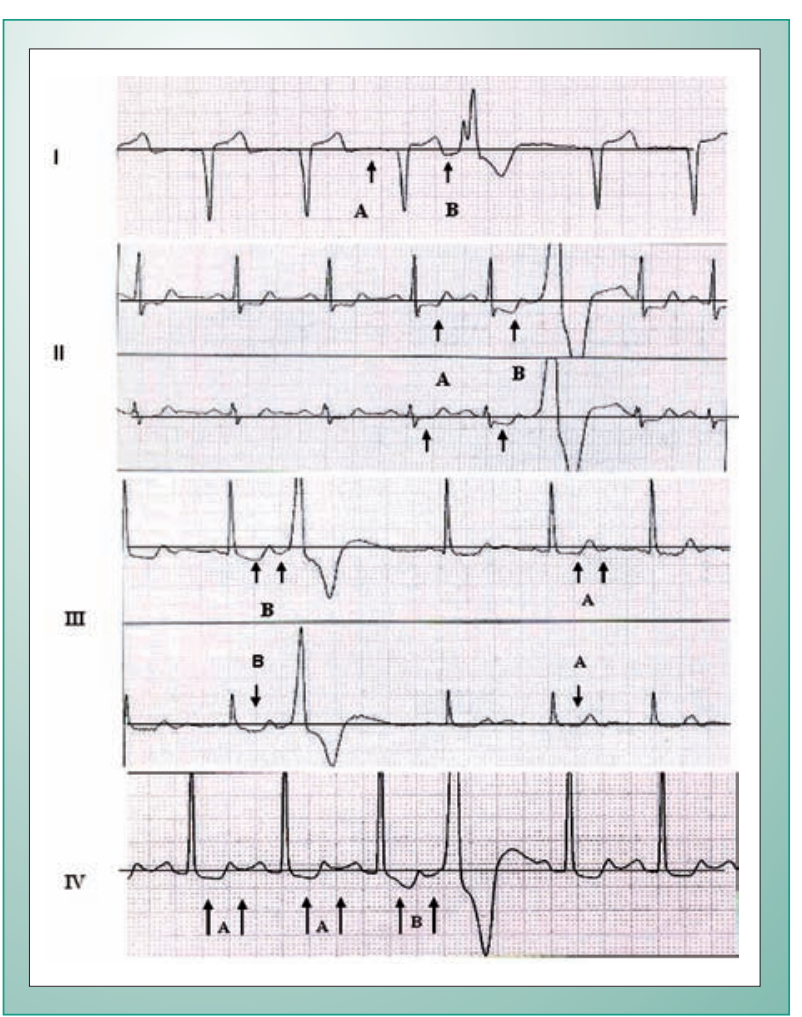

Fig. 2 - Alterações eletrocardiográficas, precedendo extra-sístoles ventriculares:

I - Infradesnivelamento da linha de base diastólica de $A$ para B

II - Infradesnivelamento do segmento ST e modificação da onda T entre os momentos $A$ e $B$.

III - Infradesnivelamento do segmento ST e aparecimento de onda $U$ negativa, quando se comparam os momentos $A$ e $B$.

IV - Acentuação do infradesnivelamento do segmento ST, da negatividade da onda $T$ e aparecimento de onda $U$ negativa do momento $A$ para $B$.

3 - Aparecimento de onda $U$ negativa (fig. 1-I, 1-V, 2-III e 2-IV).

4 - Aparecimento de infra ou supradesnivelamentos da linha de base diastólica, imediatamente antes da extra-sístole ventricular (fig. 1-II, 1-III, 2-I e 3-I).

Essas alterações não foram observadas como fenômenos isolados, não precedendo extra-sístoles.

\section{Comentários}

A eletrogênese das extra-sístoles está relacionada basicamente com o automatismo e o dromotropismo ${ }^{1}$ das fibras miocárdicas. Durante a contração ventricular, que se estende por um período que vai, no eletrocardiograma, do final do QRS ao final da onda $\mathrm{T}$, as fibras miocárdicas apresentam-se em período refratário, sendo a refratariedade a novas despolarizações absoluta nos momentos iniciais da contração e relativa nos momentos finais. Durante a diástole, as fibras apresentam potenciais elétricos intracelulares negativos em relação aos da superfície externa de sua membrana (Fase 4 do potencial de ação). Quanto mais negativo for o potencial diastólico dentro das fibras, menor será a possibilidade de manifestação de automatismo espontâneo das mesmas. Quando o potencial diastólico é menos negativo

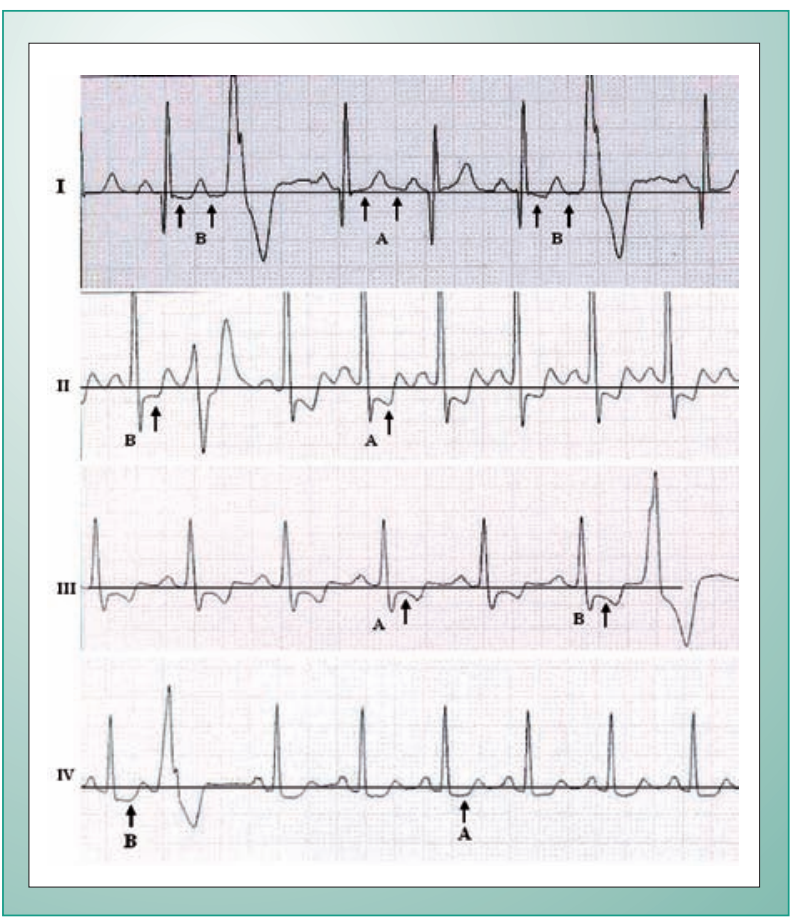

Fig. 3 - Alterações eletrocardiográficas, precedendo extra-sístoles ventriculares:

I - Infradesnivelamento do segmento ST e da linha de base diastólica, quando se comparam o momento A com os momentos B e B1 que precedem as extra-sístoles.

II - Redução do componente negativo da onda T no complexo que precede a extra-sístole em $B$ em relação a $A$.

III - Aumento do infradesnivelamento do segmento ST e da negatividade da onda $T$.

IV - Infradesnivelamento do segmento ST em B, em comparação com A.

do que deveria ser, a distribuição de cargas elétricas do miócito aproxima-se do limiar de excitabilidade, acima do qual é deflagrada a despolarização da fibra. Uma das alterações mais comumente relacionadas com o aparecimento de extrasístoles ventriculares é a heterogeneidade de repolarização em diferentes áreas miocárdicas, fenômeno conhecido como dispersão, que cria condições para a ocorrência de reentrada e para despolarizações precoces a partir de focos regionais ${ }^{2,3}$.

Embora se admita que a heterogeneidade têmporo-espacial de repolarização seja comum nas doenças cardíacas - quase tão comum como as próprias extra-sístoles ventriculares - não há referências na literatura sobre a tradução desse fenômeno de forma evidente nos eletrocardiogramas convencionais. Os padrões eletrocardiográficos descritos neste trabalho mostram que os mecanismos elétricos subjacentes ao aparecimento das extra-sístoles ventriculares freqüentemente têm alguma tradução nos traçados de superfície e merecem ser procurados em outras casuísticas, pois são os mesmos, independentemente da doença de base. Isquemia, inflamações, fibroses, agentes cardioativos, distúrbios eletrolíticos ou ácido-básicos, hiperatividade autonômica, particularmente simpática etc, habitualmente presentes em doenças cardíacas ou sistêmicas, podem causar alterações regionais dos potenciais intracelulares diastólicos, deflagrando extra-sístoles. 


\section{Referências}

1. Moffa PJ. Introdução ao estudo das disritmias cardíacas. In: Moffa Pe Sanches PCR. Eletrocardiograma Normal e Patológico. 1ạ. Ed. Editado por Ramires JAF e Oliveira AS. São Paulo: Rocca Ltda; 2001: 207-22.

2. Rubart M, Zipes DP. Genesis of cardiac arrhythmias: electrophysiological considerations. In: Braunwald ER, Zipes DP and Libby P. Heart Disease. A Textbook of Cardiovascular Medicine. 6th ed. Philadelphia: W.B. Saunders
Company; 2001: 659-99.

3. Marchiliski FE, Schwartzman G, Gottlieb CD, González-Zuelgaray J, Callans DJ. Electrical events associated with arrhythmias initiation and stimulatrion techniques for arrhythmia prevention. In: Zipes DP and Jalife J. Cardiac Electrophysiology. From Cell to Bedside. 2nd ed. Philadelphia: W.B. Saunders Company; 1995: 863-77. 